\title{
Standard precaution and incidence of needle stick injury during children vaccination among nurses working in maternal and child health centers in El-Minia governorate
}

\author{
Yosria EL- Sayed Hossein \\ Associate professor Faculty of Nursing , EL-Minia University, Egypt \\ E-mail:yosria1968@yahoo.com
}

\begin{abstract}
Background: Persons administering vaccines should follow necessary precautions to minimize risk for spreading disease. Nurses have a significant role in this process and are responsible for implementing several infection control strategies. Syringes and needles used for injections must be sterile and disposable to minimize the risk of contamination. The Centers for disease Control and prevention (CDC) estimates that each year 384,000 needle sticks injuries (NSI) and other sharp - related percutaneous injuries are sustained by hospital based healthcare personnel, an average of over 1,000 sharp injuries per day. The estimate is not including other health care settings, such as emergency services, outpatient Clinics home based care and nursing homes.

Objective: This study aims to identify the standard precaution and the Incidence of Needle Stick Injury Among nurses working in Maternal and Child Health Centers during Children vaccination in El-Minia Governorate

Material and Method: Cross sectional study was utilized to meet the aim of the study, this study was conducted in the ten(10) minister center of health (MCH) at EL- Minia from May to August 2012, the Nurses participated in this study included (100) Nurses who are working in $(\mathrm{M} \mathrm{CH})$ center after receiving their consents for participation. Observation checklist was done to observe the nurses performance before, during and after child vaccine and procedure toward universal precaution.

Results: that the highest frequency of nurses were in the age intervals $30<40$ years with main age $(34.3 \pm 9.4)$ all sample were females and secondary school degree in nursing. More than have of them 55\%were having 10:20 years of experience in nursing, Relation between nurse's incidences of needle stick injury and their experience, show statistically significant differences. Also the relation between nurse's incidences of need stick injury and their training, were good with statistically significant differences

Conclusion: The study showed a high prevalence of needle stick injuries and low of using standard precaution among nurses during vaccination the child so suggests that every $\mathrm{MCH}$ must have an infection control committee for observation the using of standard precaution and training the nurses for prevention of needle stick injury.
\end{abstract}

Keywords: Standard Precaution; Needle Stick; Nurses; Vaccination.

\section{Introduction}

Staff use of standard precaution (otherwise known as universal precaution or body substance isolation) provides the basic level of infection control (Mark and David, 2009). Standard precautions are to be followed at all times by nurses because we can never be sure of client's infectious status, all exposures of blood or other body fluids have the potential to cause infection. It is vital to protect the nurse and other client (Rosdahl Kowalski2008).

Standard precaution promote: hand washing, the use of gloves, masks and gowns when appropriate for children contact, gloves, mask and gowns are part of the health care providers (personal protective equipment or (PPE). Each is considered a barrier devise designed to prevent direct contact with blood or body fluid (Pillitteri, 2007).

\subsection{Vaccine administration}

Appropriate vaccine administration is critical to vaccine effectiveness. The recommended site, route and dose for each vaccine are based on clinical trials, practical experience and theoretical considerations Vaccine safety issues and need for multiple injections have increased the concerns and anxiety associated with immunization. Healthcare providers need to display confidence and establish an environment that promotes a sense of security and trust for the patient and family, utilizing a variety of techniques to minimize the stress and discomfort associated with receiving injections. This is particularly important when administering vaccine to children (Gray, et al., 2009).

\subsection{Subcutaneous injection :(SC) injection}

Injections are administered into the fatty tissue found below the dermis and above the muscles tissue. Subcutaneous tissue can be found all over the body. The usual sites for vaccine administration are the high (for infants $<12$ months of age) and the upper outer triceps of the arm (for person > 12 months of age) (Centers for disease Control and prevention, 2009). 


\subsection{Intramuscular injection: (IM) injection}

(IM) injections are administered into muscle tissue below the dermis and subcutaneous tissue. Although there are several IM injection sites on the body, the recommended IM sites for vaccine administration are the vastus lateralies muscle

(Anterolateral high) and the deltoid muscle (upper arm). The site depends on the age of the individual and the degree of muscle development (Ruth Jane, 2003).

\subsection{Intradermal injection: (ID) injections}

ID injections are usually administered on the flexor surface of the forearm. The bevel of the needle should be turned upwards and at angle parallel to the forearm. The needle is inserted so that the bevel penetrates the skin, if done correctly, a small bleb should be observed at the injection site upon injection of the vaccine (Public Health Agency of Canada, 2006).

\subsection{Needle stick injury}

The free medical dictionary define needle stick injury as an accidental skin penetrating stab wound from a needle or other sharp object that may result in exposure to blood other body fluids. These events are of concern because of the risk to transmit blood borne disease through the passage of the hepatitis Virus (H BV,), the hepatitis c virus (HCV), and the Human Immunodeficiency Virus (HIV) (M.saia \& F.Hofmann, 2010).

Needle sticks and sharp injuries (NSSIS) have been recognized as one of the common occupational hazards among heath care workers. The study concerning exposures to blood and bodily fluids in health care workers found that on average $93.7 \%$ per 1000 health care employees were exposed annually ( T.C,Goob et al, 2000). The majority of the exposures were found to occur in nursing personnel, with $35 \%$ of total exposures occurring via needle sticks (D.L., Gurubacharya et al., 2003).

Needle stick and sharp injuries (NSI) are accidental skin penetrating wounds caused by sharp instruments in a medical setting. They are defined as an accidental skin penetrating wound caused by hollow bore needles such as hypodermic needles, blood collection needles, intra- venous (IV) catheter styles, and needles used to connect parts of IV delivery system, scalpels and broken glass. Healthcare Workers (HCWs) face a high risk of an occupational exposure to blood Workers (HCWs)

Which can lead to the transmission of pathogens causing an infection?

And resulting in hazardous consequences for their health. Hepatitis B, Hepatitis C, and Human Immunodeficiency Virus (HIV) are of utmost concern because they can cause significant morbidity or death. The common high risk situation of such an occupational exposure is percutaneous injury which is a high risk injury.The frequency of such events has been estimated to be about 800,000 cases in the United State of America alone (A. Hashmi et al.,2012). Another investigation estimates the rates of injuries on a global level to affect about 3.5 million individuals (Prusset al., 2005). Among nurses and physicians appear especially at risk; [3] and an investigation healthcare workers among American surgeons indicates that almost every surgeon experienced at least one such injury during their training (Makary, et al., 2007). Causes of sharps injury include various factors like type and design of needle, recapping activity, handling/transferring specimens, collision between HCWs or sharps, during clean-up, manipulating needles in patient line related work, passing/handling devices or failure to dispose of the needle in puncture proof containers (Wilbum 2004).The introduction of safety devices is one of the main starting points for avoidance of needle-stick injuries, and acceptance among healthcare workers is high. Further targets for preventive measures, such as training in safe working routines, are necessary for improvement of safe work conditions (Wicker et al., 2008). Engineered devices can significantly reduce the incidence of such injuries even cost analyses indicate that use of these devices will be cost-effective in the long term. But introduction of such devices should accompanied with the necessary education and training, as part of a comprehensive sharps injury prevention and control program (Tan, 2011).A British study states that less number of NSIs occurs when using safety syringes and to avoid NSIs, education plays a vital role particularly with effective implementation of the change to safety syringes with appropriate training (Gaballah, et al, 2012). Healthcare organizations can improve staff safety by investing wisely in educational programs regarding approaches to minimize NSIs risks.

\subsection{Significance of the study}

Much injury can be attributed to improper work practices. Example include injuries that occur while sharp are being passed between different individuals, or transferred to a different location, due to recapping during collisions between workers, and during documentation or processing of used equipment. Personnel are also injured by the improper disposal of used sharps, such as when sharps are left in unusual locations including laundry, struck in mattresses, left in pockets, and left on tables, trays, or other surfaces. The design of needles and other sharps can impact the risk of injury. Specific devices that have an increased risk of NSI are, hollow- bore needles, devices that must be taken a part or manipulated by the health care worker, syringes that retain an exposed needle after use, and needles attached to tubing ( American Nursing Association, 2011).

\subsection{Needle stick or sharp injuries prevention}

Inappropriate handling of sharp is a major cause of accidental exposure to blood- borne viruses in health settings. To minimize the risk of a needle stick or sharp injuries, needle, sharps and clinical waste should be handled carefully at all times (W.H.O, 2009). Specifically, clinician and other health care worker should:

- $\quad$ Minimize their handling needles, sharps and clinical waste.

- Not bend or recap needles or remove needles from disposable syringes.

- Use safe needle - handling systems including rigid containers for disposable, which should be kept out of the reach of toddlers and small children.

- $\quad$ Ensure sharp containers are available at the point of use or in close proximity to work sites to aid easy and immediate disposal (Suzanne, 2003).

Fortunately NSI are preventable through sharps elimination, engineering controls (engineered safety devices), work practice controls, and establishment of safety culture and climate, all of which are elements of a successful sharp in injury prevention program. The first step in the hierarchy of controls is through engineering the most effective way to safeguard against any occupational hazard is through hazard elimination or substitution

There are several ways that needle and other sharp use can be eliminated or reduced. A prime example is the use of needle - free IV delivery systems that do not require needle access. According to the CDC, ,approximately $85 \%$ of US hospitals have eliminated unnecessary use of needle, and therefore reduced IV- related sharps injuries, through implementation of these devices(American Nursing Association, 2011).

\subsection{Purpose of the study}

Persons administering vaccines should follow necessary precautions to minimize risk for spreading disease.

Nurses have a significant role in this process and are responsible for implementing several infection control strategies.

\subsection{Questions of the study:}

The central questions that will guide this inquiry are the following: 1) Are there any statistically significant differences between nurse's incidences of needle stick injury and their experience? 
2) Are there any statistically significant differences relation between nurse's incidences of need stick injury and their training.

\section{Subject and method}

\subsection{Research design}

Cross Sectional was utilized to meet the aim of the study.

\subsection{Setting}

This study was conducted in the Ten Ministry Center of Health $(\mathrm{MCH})$ at EL Minia (5 MCH center in EL- Minia City and $5 \mathrm{MCH}$ center in EL- Minia district)

\subsection{Subjects}

The subjects who participated in this study included 100 nurses females who are working in the previous mentioned after receiving their consents for participation in the research

\subsection{Tools of data collection}

It consisted of two parts:

The first part: was concerned with personal and socio - demographic characteristic of studied sample it include age, sex marital status, level of education, residence, years of experiences

The second part: covered Performance of the studied sample .It included designed observational checklist to evaluate the performance of the sample regarding Standard precaution and Incidence of Needle Stick Injury during Children vaccination

- Precaution related to safe intramuscular injection checklist.

- Precaution related to safe subcutaneous injection checklist.

- Precaution related to safe intradermal injection checklist.

\subsection{Methods of data collection}

Before starting this study, it was necessary to secure the approval of authorities in the setting of the study; therefore, permission was obtained from the director of $\mathrm{MCH}$ centers.

Data collection was done by researcher. Observation was done during routine work of the centers. Nurses have ethical rights to participate or refuse participation of the study.From May to August 2012

\subsection{Statistical design}

In the performance observation checklist, score (one) was given for each correct step done and score (zero) for incorrectly done or not done

Poor score (less than 50\%) and good score is more than 50\%)

\subsection{Statistical analysis}

Data entry and analysis were done using the statistical software program SPSS version 13the data were presented in the form of percentages and mean \pm standard deviation. $P$ value less than 0.05 was considered significant. Chi Square test were used

\section{Results}

Table 1: Distribution of the Studied Sample Regarding their Socio- Demographic Characteristics.

\begin{tabular}{|c|c|c|}
\hline Characteristics & $\mathrm{NO}=100$ & $\%$ \\
\hline $\begin{array}{l}\text { Age group } \\
-<30 \\
-<40 \\
-<50 \\
->60 \\
\text { Mean } \pm \text { SD }\end{array}$ & $\begin{array}{l}25 \\
53 \\
15 \\
7 \\
34.3 \pm 9.4\end{array}$ & $\begin{array}{l}25 \% \\
53 \% \\
15 \% \\
7 \%\end{array}$ \\
\hline $\begin{array}{l}\text { Sex } \\
\text { Female }\end{array}$ & 100 & $100 \%$ \\
\hline $\begin{array}{l}\text { Residence } \\
\text { Minia city } \\
\text { Minia district }\end{array}$ & $\begin{array}{l}30 \\
70\end{array}$ & $\begin{array}{l}30 \% \\
70 \%\end{array}$ \\
\hline $\begin{array}{l}\text { Years of experience } \\
-<5 \\
-<10 \\
-<20 \\
-20+ \\
\text { Mean } \pm \text { SD }\end{array}$ & $\begin{array}{l}6 \\
19 \\
55 \\
20 \\
15.4 \pm 9.2\end{array}$ & $\begin{array}{l}6 \% \\
19 \% \\
55 \% \\
20 \%\end{array}$ \\
\hline $\begin{array}{l}\text { Qualification } \\
\text { - diploma }\end{array}$ & 100 & $100 \%$ \\
\hline $\begin{array}{l}\text { Training course about infection control } \\
\text { - Yes } \\
\text { - No }\end{array}$ & $\begin{array}{l}42 \\
58\end{array}$ & $\begin{array}{l}42 \% \\
58 \%\end{array}$ \\
\hline $\begin{array}{l}\text { Frequency Number of episode of needle stick injury } \\
\text { among studied sample } \\
0 \text { episode } \\
1 \text { episode } \\
2-4 \text { episode } \\
\text { > } 4 \text { episode }\end{array}$ & $\begin{array}{l}28 \\
18 \\
30 \\
24\end{array}$ & $\begin{array}{l}28 \% \\
18 \% \\
30 \% \\
24 \%\end{array}$ \\
\hline
\end{tabular}

Table (1) displays demographic characteristics of the studied sample .It reveals that the highest frequency of nurses were in the age intervals $30<40$ years with main age $(34.3 \pm 9.4)$ all samplewere females and secondary school degree in nursing. More than have of them 55\%were having 10:20 years of experience in nursing. Related attending courses about safety precaution and courses of infection control during vaccination it was found that $58 \%$ of nurses didn't attend. RegardingFrequency number of episode of needle stick injury among studied sample was found $30 \%$ of nurses exposed to needle stick injury.

Table 2: Frequency Distribution of Nurse's Performance during Hand Washing

\begin{tabular}{|c|c|c|c|c|}
\hline \multirow{3}{*}{ Items } & \multicolumn{4}{|c|}{$\mathrm{No}=100$} \\
\hline & \multicolumn{2}{|c|}{ Done } & \multicolumn{2}{|c|}{ Not done } \\
\hline & No & $\%$ & No & $\%$ \\
\hline 1- remove jewelry & 17 & $17 \%$ & 83 & $83 \%$ \\
\hline $\begin{array}{l}\text { 2-stand in front of the sink and avoid lean- } \\
\text { ing against it }\end{array}$ & 40 & $40 \%$ & 60 & $60 \%$ \\
\hline $\begin{array}{l}3 \text {-turn on the water and regulate its flow } \\
\text { and temperature }\end{array}$ & 44 & $44 \%$ & 56 & $56 \%$ \\
\hline $\begin{array}{l}\text { 4-wet your hand and forearms with water } \\
\text {,keeping the hands lower than elbows }\end{array}$ & 39 & $39 \%$ & 61 & $61 \%$ \\
\hline 5-apply an antibacterial liquid soap & 40 & $40 \%$ & 60 & $\begin{array}{l}60 \\
\%\end{array}$ \\
\hline $\begin{array}{l}\text { 6-wash your hand,wrists, and lower fore- } \\
\text { arms for a minimum of } 10-15 \text { seconds, } \\
\text { interlace the fingers and rub the hand back } \\
\text { and forth }\end{array}$ & 42 & $42 \%$ & 58 & $58 \%$ \\
\hline $\begin{array}{l}\text { 7-insert the finger nails from one hand } \\
\text { under those of the other hand }\end{array}$ & 17 & $17 \%$ & 83 & $83 \%$ \\
\hline $\begin{array}{l}\text { 8-using a sweeping motion to clean them, } \\
\text { repeat with the other hand } \\
\text { 9- rinse through for at least } 10 \text { second }\end{array}$ & 40 & $40 \%$ & 60 & $60 \%$ \\
\hline ,keeping the hands lower than the forearms & 44 & $44 \%$ & 56 & $56 \%$ \\
\hline 10 -dry the hand with paper towel & 43 & $43 \%$ & 67 & $67 \%$ \\
\hline 11-wash your hands after each contact & 17 & $17 \%$ & 83 & $83 \%$ \\
\hline
\end{tabular}


This table illustrated that $17 \%$ only of nurses remove jewelry, insert the finger nails from one hand under those of the other hand and the same wash your hands after each contact.

Table 3: Frequency Distribution of Nurse's Performance According to Wearing Gloves

\begin{tabular}{lllll}
\hline \multirow{2}{*}{ Items } & \multicolumn{3}{l}{ No= 100} & \\
& Done & \multicolumn{2}{l}{ Not done } \\
& No & $\%$ & No & $\%$ \\
\hline 1-wash the hand and dry thoroughly & 8 & $8 \%$ & 92 & $92 \%$ \\
2-choose correct size glove & 12 & $12 \%$ & 88 & $88 \%$ \\
3-bunch the glove up and then pull it on to the & 12 & $12 \%$ & 88 & $88 \%$ \\
hand ease the fingers into the glove. & 10 & $10 \%$ & 90 & $90 \%$ \\
$\begin{array}{l}\text { 4-repeate for other hand } \\
\text { 5-change gloves after each contact with a } \\
\text { child, and if gloves become perforated }\end{array}$ & 17 & $17 \%$ & 83 & $83 \%$ \\
\hline
\end{tabular}

Table (3): shows distribution of the nurses with correct performance concerning wearing gloves. As shown in the table the great majority of them $92 \%$ didn't wash the hand and dry thoroughly.

Table 4: Distributionof Nurse'sperformance Concerning To Administrating Injection Vaccine (Intramuscular, Subcutaneous and Intradermal).

\begin{tabular}{|c|c|c|c|c|}
\hline \multirow{3}{*}{ Items } & \multicolumn{4}{|c|}{$\mathrm{No}=100$} \\
\hline & \multicolumn{2}{|c|}{ Done } & \multicolumn{2}{|c|}{ Not done } \\
\hline & No & $\%$ & No & $\%$ \\
\hline \multirow{5}{*}{$\begin{array}{l}\text {-Remove the cap from the syringe } \\
\text { - insert the needle quickly in right angle } \\
\text { dispose the needle and syringe in appropriate } \\
\text { receptacle } \\
\text { - remove the needle } \\
\text {-place uncapped syringe and needle directly } \\
\text { in biohazard puncture- proof container }\end{array}$} & 97 & $97 \%$ & 3 & $3 \%$ \\
\hline & 96 & $96 \%$ & 4 & $4 \%$ \\
\hline & 99 & $99 \%$ & 1 & $1 \%$ \\
\hline & 100 & $100 \%$ & 0 & $0 \%$ \\
\hline & 96 & $96 \%$ & 3 & $3 \%$ \\
\hline
\end{tabular}

In this table shows theDistribution of nurse's performance concerning to administrating injection vaccine (Intramuscular, Subcutaneous and Intradermal). It was found that the whole sample have done remove the needle.Also satisfactory performance of the majority of the sample (99\%) has done dispose the needle and syringe in appropriate receptacle.

Table 5: Preventive Measures/Safety Practices Followed By the Studied Sample during Different Procedures

\begin{tabular}{lllllll}
\hline $\begin{array}{l}\text { Preventive } \\
\text { measures/ safe- }\end{array}$ & \multicolumn{2}{l}{$\begin{array}{l}\text { Use of protec- } \\
\text { tive gloves }\end{array}$} & \multicolumn{2}{l}{$\begin{array}{l}\text { Proper disposal } \\
\text { of sharp }\end{array}$} & \multicolumn{2}{l}{$\begin{array}{l}\text { Recapping of } \\
\text { needles }\end{array}$} \\
& NO & $\%$ & No & $\%$ & No & $\%$ \\
\hline Always & 8 & $8 \%$ & 20 & $20 \%$ & 46 & $46 \%$ \\
Often & 22 & $22 \%$ & 30 & $30 \%$ & 30 & $30 \%$ \\
Sometimes & 30 & $30 \%$ & 23 & $23 \%$ & 10 & $10 \%$ \\
Rarely & 25 & $25 \%$ & 20 & $20 \%$ & 10 & $10 \%$ \\
Never & 15 & $15 \%$ & 7 & $7 \%$ & 4 & $4 \%$ \\
Total & 100 & $100 \%$ & 100 & $100 \%$ & 100 & $100 \%$ \\
\hline
\end{tabular}

In table (6) .It was found that the minority of nurses sometimes use of protective measures , also often used proper disposal of sharp and always recapping of needle $(30 \%, 30 \%$ and $46 \%$ respectively ).

Table 6: Distribution of the Scorning on Nurse Using Protective Measures During Vaccination

\begin{tabular}{llll} 
During Vaccination & \multicolumn{3}{l}{ Scoring } \\
\hline \multirow{2}{*}{ Nurses using protective measure } & No=100 & \\
& Poor & good & P.value \\
\hline Hand washing & $52 \%$ & $48 \%$ & 0.1 \\
Wearing gloves & $98 \%$ & $2 \%$ & $0.003^{*}$ \\
I.M injection vaccine & $10 \%$ & $90 \%$ & 0.005 \\
SC injection vaccine & $15 \%$ & $85 \%$ & $0.003^{*}$ \\
ID injection vaccine & $8 \%$ & $92 \%$ & $0.003^{*}$ \\
\hline
\end{tabular}

Table 6: It shows the distribution of the scoring nurse's using Protective Measures during vaccination. Regarding protective measures (hand washing and wearinggloves) it was found that the highest percentage of nurses had poor score (52\% and 98\% respectively). Conversely regarding to percentage related to administration of vaccine (IM, SC and ID injection), the great majority of the study subjects had good scoring $(90 \%, 85 \%$ and $92 \%$ respectively).

Table 7: Relation between Nurse's Incidences of Needle Stick Injury and Their Experience.

\begin{tabular}{|c|c|c|c|c|c|c|c|c|}
\hline $\begin{array}{l}\text { Years of } \\
\text { experience }\end{array}$ & Poor & & Goc & & Total & & \multicolumn{2}{|c|}{$\begin{array}{l}\text { P value } \\
\text { Fisher } \\
\text { exact }\end{array}$} \\
\hline \multirow{2}{*}{$<5$} & No & $\%$ & No & $\%$ & No & $\%$ & \multirow{6}{*}{8.5} & \multirow{6}{*}{$0.04 *$} \\
\hline & 2 & & 5 & & 3 & $100 \%$ & & \\
\hline$<10$ & 3 & & 15 & & 22 & $100 \%$ & & \\
\hline$<20$ & 15 & & 40 & & 50 & $100 \%$ & & \\
\hline$>20$ & 10 & & 10 & & 25 & $100 \%$ & & \\
\hline Total & 30 & $30 \%$ & 70 & $70 \%$ & 100 & $100 \%$ & & \\
\hline
\end{tabular}

Table (7): Relation between nurse's incidences of needle stick injury and their experience, show statistically significant differences (PV) 0.04. It is evident that there is a negative correlation between years of experience and the good performance.

Table 8: Relation between Nurse's Incidences of Need Stick Injury and Their Training

\begin{tabular}{lllllllll}
\hline Training & Poor & \multicolumn{3}{c}{ Good } & \multicolumn{3}{c}{ Total } & \multicolumn{3}{l}{ P value } \\
course & No & $\%$ & N & $\%$ & No & $\%$ & Fisher exact \\
\hline Yes & 4 & & 34 & & 38 & $100 \%$ & & \\
No & 26 & & 36 & & 62 & $100 \%$ & 13.5 & 0.001 \\
Total & 30 & $30 \%$ & 70 & $70 \%$ & 100 & $100 \%$ & & \\
\hline
\end{tabular}

Table (8): (PV) 0.001. Consequently there is a positive correlation between training and the nurse's good performance.

\section{Discussion}

Standard precautions are to be followed at all times by nurses, because we can never be sure of a client's infection status, all patients are treated as if they are infected. All exposure to blood or other body fluids have the potential to cause infection. It is vital to protect the nurse and other clients (Arnoled, 2009). Standard precaution are good hygiene habits, such as hand washing, wearing gloves, correct sharps handling and aseptic technique ( Kendall,2003).

Needle stick injuries (NSI) are the commonest route by which blood-borne viruses and/or infections such as HIV and hepatitis B and $\mathrm{C}$ are transmitted from patients to healthcare workers. Such infections serve as high occupational risks and threats to healthcare workers, especially where basic rules of occupational safety and health are not implemented. The risk of contracting acute hepatitis $\mathrm{C}$ infection due to a needle prick injury is estimated to range from $1 \%$ to $5 \%$ (Joint WHO/ILO, 2005).

The findings of this study reveal that $53 \%$ of nurse's age was ranging from 30-40 years with Mean (34.3 \pm 9.4).More than half of nurses $55 \%$ of the nurse's experiences

We're ranging from 10: 20 years with $(15.4 \pm 9.2)$. As for qualification, all nurses $100 \%$ had a secondary school degree. Regarding training courses about safety procuration related vaccination it was noticed that $58 \%$ of the studied sample did not attend any training courses. Our results agreed with (Regina et al2002\&Mohammed 2010)who reported that $64.4 \%$ and $54.6 \%$ of nurses respectively had not attend any training courses related to universal precautions. Regarding frequency Number of episode of needle stick injury among studied sample it was noticed that $30 \%$ of the studied sample exposed to 1 episode of needle stick injury,

In 2005, a study was conducted among Australian medical undergraduates in whom $13.8 \%$ had suffered a total of 41 Needle stick and Sharps Injuries (NSI) incidents.

(Twitcheil KT, 2003). In a study on French students, $25 \%$ of the respondents had experienced an exposure accident by needle prick (15). In 2003 a study was conducted in Missouri, USA, in which 43 out of 224 students $(19.2 \%)$ reported needle stick injuries (Patterson JM, etal. 2003).

The present study performance of safety precaution (hand washing and wearing gloves) was poor. This finding are in accordance with 
(kandel 2003) who reported poor practices regarding infection control precautions such as hand washing, wear gloves and patient care equipment. The findings of this study illustrated that more than of the studied nurses $58 \%$ didn't wash their hands, and $17 \%$ only wash hand between each contact. This may be due to the increasing number of children and the shortage of trained nurses. This is in agreement with (Kamal 2004) who observed that $33.3 \%$ of nurses had poor practice among hand washing procedure. On the other hands, these finding are in opposition to the results of (berhe et al 2005) who found that $77 \%$ of registered nursesreported hand washing at the time before and after patien contact. This study showed that $17 \%$ only of nurses remove jewelry, insert the finger nails from one hand under those of the other hand and the same wash your hands after each contact. These results are in accordance with Mohamed 2010 who also found that none of her studied sample remove jewelry before hand washing .This may be a result of shortage of knowledge on nursing curriculum related to infection control and absence or insufficient training in this area of clinical practice.

In relation to studied sample performance regarding safe injection.It was found that the whole sample have done remove the needle .Also satisfactory performance of the majority of the sample $(99 \%)$ has done dispose the needle and syringe in appropriate receptacle. These finding are consistent with the result of Shehata 2011 who reported that all the study sample (100\%) use disposal syringe and use new syringe for each injection. Also the result of Mohamed 2010 who reported that most of the observed nurses 97.9\% use disposable and new syringe for each injection. To prevent needle-stick injury or reuse, needles and syringes should be discarded immediately after use in labeled, puncture proof container (Andrew et al., 2006) emphasized that to minimize the risk of a needle stick or sharps injury and clinical waste should be handled carefully at all times, nurses should not bend or recap the needle, use safe needle- handling systems including rigid containers are available at the point of use for immediate disposal.

It was found that the minority of nurses sometimes use of protective measures, also often used proper disposal of sharp and always recapping of needle $(30 \%, 30 \%$ and $46 \%$ respectively). These rates are similar to those of the observed by(Fahim 2008) who reported that only $5.9 \%$ of the studied population wore protective gloves on a regular basis; only $16.6 \%$ of the workers safely discard the sharp objects; more than $60 \%$ ) more or less neglected this measure, creating potential hazards for the workers involved in waste disposal. It was found that $46.7 \%$ of workers always recap needles, a practice considered by some studies as the most risky practice. Raising awareness of the risk of exposure among health care workers is needed. Also the presence of occupational exposures reporting system to an employee health service is required to ensure appropriate counseling, facilitate prophylaxis or early treatment, and establish legal prerequisites for workers' compensation. Hepatitis B vaccination among health care workers should be available with ensuring the completed doses and checking immunity status. The common practice of bending and recapping of the needles must be combated by all means. Similar studies are needed to assess the risk of exposure incidents in different healthrelated professions and high risk areas and to establish appropriate prevention guidelines.

In addition, the results of this study revealed that nurses incidences of needle stick injury and their experience. The nurse who work experience with 5 years' experience or less were good .This finding is in agreement with (Shehata 2011)who reported that the nurses practice who have work experience with 5 years' experience or less were satisfactory, better than those who have work experience $<10$ years. $<20$ years, and 20 years and more. Also agreement with (Gamal 2005) who found that nurses performance having work experience from 1-5 years were higher than those who having work experience ranging from 5-10 years, 10-15 years and 15 and more. This might be due to nurses who have more experience will be responsible for administrative and managerial activities . While younger ones have more practical work in direct patient care, and the newer graduates have fresher and more update knowledge than older nurses.

At the end it was noticed that there is a positive correlation between training and the nurse's good performance. These finding is in agreement with (Shehata 2011) who reported that $94.1 \%$ showed good practices in group which attended training course program than those with no training courses. Also agreement with (Abolwafa 2009) who indicated that total scores of nurses' knowledge and performance who attended training courses about infection control were higher than those who didn't attend.

\section{Conclusion and recommendation}

Based on the results of this study, it can be concluded that

- Regarding protective measures (hand washing and wearing gloves) it was found that the highest percentage of nurses had poor score (52\% and $98 \%$ respectively).

- There is a negative correlation between years of experience and the good performance.

- The results of this study indirectly point to the fact that there is a risk of acquiring blood-borne infections through needle stick injury.

- The study indicating a lack of adequate knowledge among these Nurses about the consequences of needle Stick injuries.

- There is goodrelation between nurse's incidences of need stick injury and their training,

- It was found that the minority of nurses sometimes use of protective measures, also often used proper disposal of sharp and always recapping of needle

- Every MCH must have an infection control committee (such as protective measure, sinks, soap, towel and septic solution)

- Provision of continuing education programs in regular basis in order to refresh and update nurse's knowledge.

- Perform on job training for nurses to evaluate performance

- Therefore it is recommended that universal precaution and the nursing curriculum should include the content on how to recap the needle safely and how to handle used syringe safely.

- Therefore, nurses, especially young staff, need continuing education and training about prevention of SIs as this contributes to improved attitudes and would decrease SIs. The $\mathrm{MCH}$ needs to evaluate a training program regularly to avoid inadequate training in the prevention of SIs.

\section{Acknowledgement}

We wish to thank all the nurses who participated in this study who facilitated this research.

\section{References}

[1] M. Honda., (2011): Sharps Injuries among Nurses in a Thai Regional Hospital: Prevalence and Risk Factors, Institute for Health Development, Mahidol University, Thailand.

[2] Ayman Ekram Fahim., (2008): Sharp Devices Injuries among Resident Physicians and Nurses in Suez Canal University Hospital.

[3] Mark A.H, and David G.N., (2009): Rogers hand book of pediatric intensive care. Standard precautions, 4th ed. Lippincott Williams and Wilkins Company, pp,591-529

[4] Rosdahl C.B Kowalski M.T., (2008): Text Book of basic nursing. Medical asepsis 9th ed, United States of America, Lippincott Williams and Wilkins Company, pp., 429-439.

[5] PillitteriA., (2007): Maternal \&Child Health Nursing Care of the Childbearing Family, Nursing Care of the Child with an infectious disorder, 5thed, Lippincott Williams \& wilkins, pp.1349-1352.

[6] Gray D., Grantland J., and DianaM. (2009).Colorado Immunization Manual Administration Techniques, section 9.

[7] Centers for disease Control and prevention, (2009): General recommendation on immunization. Vol.511NO.RR-2, vaccine storage and handling. http://www.cdc.gov/mmwr/pdf/rr5102.pdf. 
[8] (Ruth C.B and Jane W.B., (2003: Clinical skills manual for pediatric nursing caring for children .Infection control methods, 3rd edition, upper saddle river, prentice hall company, pp. 17-18

[9] Public Health Agency of Canada, (2006): Canadian Immunization Guide. Part 1 general guidelines, vaccine administration practices, 7 th edition.

[10]M.saia \& F.Hofmann, (2010): Needle sticks injuries, incidence and cost in the United States, UnitedKingdom, Germany, France, Italy and Spain, Biomedicine International. PP41-49.

[11]T.C. Goob, S.M.Yamada, R.E. Newman\&M, Cashman, (2000): Blood borne exposures at a United States Army Medical Center .Appl Occup EnvironHyg..PP.20-25.

[12]D.L., Gurubacharya, K.C. Mathura,D.B. Karki, (2003):Knowledge, attitude and practice among health care workers on needle- stick injuries, kathmandu medical collage journal, pp. 91-94 .

[13]Anjum Hashmi., Samer Abu Al Reesh \&Lisa Indah, (2012):Prevalence of Needle- Stick and Sharp Injuries among Healthcare Workers,Najran,Saudi Arabia, Epidemiolgy Journal, Volume 2,Issue2.

[14]Prüss-Ustün A, Rapiti E, Hutin Y (2005): Estimation of the globalburden of disease attributable to contaminated sharps injuries among health-care Workers. Is J Ind Med 48: 482-490 http://dx.doi.org/10.1002/ajim.20230.

[15] Makary MA, Al-Attar A, \& Hoizmueller CG, (2007): Needle - stick injuries among surgeons in training NEngl J Med 356. 2693-2639. http://dx.doi.org/10.1056/NEJMoa070378.

[16]Wilburn SQ, (2004): Needle Sticks and Sharp injury Prevention. Online J Issues Nurs 30: 5.

[17]Wicker S, Ludwig AM, \& Gottschalk, (2008): Needle Stick injuries among health care workers, occupational hazard or avoidable hazard, 120, PP. 486- 492.

[18]Tan L., Hawk JC3rd \& Sterling ML, (2011): Report of the council on Scientific Affairs, preventing needle Stick injuries in health care setting. Arch Intern Med 161: pp. 929-936. http://dx.doi.org/10.1001/archinte.161.7.929.

[19]Gaballah K, WarbutonD. Sihmbly K. \& RentonT. (2012): Needle Stick injuries among dental students. Risk factors and recommendations for prevention. Libyan J Med.

[20]American Nursing Association, (2011): ANA Backgrounder, Needlestick and Sharp Injuries.

[21]WHO (World Health Organization), (2009): Data statistics and graphic, country selection from immunization profile - Egypt.

[22]Suzanne p., (2003): Isolation Precautions Training Hand book for Nursing and Clinical Professionals. Basic infection control practices, 1ST Ed, Hcpro, United States of America, and PP.1-9.

[23]Arnoled Jacobsong, (2009): Policy for staff on the use of standard precaution procedures, Standard precaution understood and practical, 4th Ed, NHS Company, United States of America, pp. 1-8.

[24]Kendall, K.J., (2003): Practical Approaches to Infection Control in Residential Aged Care. Infection control overview 2nd ed., Australia, Mel Bourne Company, PP. 15- 40.

[25]Joint WHO/ILO, (2005): Guidelines on health services and HIV/AIDS; June $2005 . \quad$ Available at: www.who.int/hiv/pub/guidelines/ilowhoguidelines_ru.pdf (Accessed 23/07/2007).

[26]Regina C., Molassiotis A., and Eunice C., (2002): Nurses knowledge and compliance with universal precautions in an acute hospital international journal of nursing studies, 39(8), pp.163-175.

[27]Mohammed F.M., (2010): Knowledge practice and attitude of nurses toward universal precautions in outpatient clinics at Assiut university hospitals. Master thesis, department of C.H.N., Faulty of nursing, Assiut University.

[28] Twitcheil KT, (2003):Bloodbome pathogens: what you need to know Part I. AAOHN J

[29]Patterson JM, Novak CB. Mackinnon SE, Ellis RA., (2003): Needle stick injuries among medical students. Is J Infection Control 31: 226 230 ? http://dx.doi.org/10.1067/mic.2003.44.

[30]Kamal A., (2004): Assessment of health team knowledge and practice about infection control in maternal child health centers in Assiut city. Master thesis, department of Community Health Nursing, Faculty of nursing, Assiut University.

[31]Berhe, M., Michael.B. Edmond M. And Gonzalo, M., (2005): practice and an assessment of health care workers perceptions of compliance with infection, Am J Infect control 33, pp.55-57. http://dx.doi.org/10.1016/j.ajic.2004.07.011.

[32] Shehata, H., B, (2011): Assessment of Nurses Practice Related to infection control during vaccination in children at EL - Minia, Master theses in Pediatric Nursing.

[33]Gamal L.M., (2005): Establishing standards for prevention of nosocomial infection in the recovery rooms and surgical ward at EL-Minia
University hospital. For doctoral degree in critical care nursing, faculty of nursing Assiut University. 